\title{
MESQUITA E O GRUPO DE ESTUDOS: HOMENAGEM PÓSTUMA AO PROFESSOR EMÉRITO JOSÉ IGNACIO BOTELHO DE MESQUITA
}

PROFESSOR MESQUITA AND THE STUDY GROUP: A POSTHUMOUS TRIBUTE TO EMERITUS

PROFESSOR JOSÉ IGNACIO BOTELHO DE MESQUITA

\section{Walter Piva Rodrigues* \\ Rodolfo da Costa Manso Real Amadeo**}

\begin{abstract}
Resumo:
Homenagem póstuma ao Professor Emérito José Ignacio Botelho de Mesquita por ocasião do ano em que ele completaria oitenta e cinco anos de vida.

Palavras-chave: Homenagem póstuma. Professor Emérito José Ignacio Botelho de Mesquita.
\end{abstract}

\begin{abstract}
:
Posthumous tribute to Emeritus Professor José Ignacio Botelho de Mesquita, by occasion of his $85^{\text {th }}$ birth anniversary.
\end{abstract}

Keywords: Posthumous tribute. Emeritus Professor José Ignacio Botelho de Mesquita.

A Revista da Faculdade de Direito da USP, das nossas tradicionais Arcadas do Largo de São Francisco, nos abriu a possibilidade de relembrarmos do aniversário que, em 11 de julho de 2020, o Professor Emérito José Ignacio Botelho de Mesquita comemoraria Oitenta e Cinco anos.

Em $1^{\circ}$ de junho de 2005, ao dar a última aula para a Graduação, no Salão Nobre da Faculdade de Direito, a única Escola em que ele foi um assíduo Docente, contando com a presença de seus familiares queridos, alunos estimados e ex-alunos de consolidadas profissões jurídicas, alguns integrantes do Corpo Docente e demais Colegas da Congregação, o Professor Mesquita bateu o ponto favorável à nossa convivência no Estado Democrático de Direito, alertando sobre o risco de o Direito Processual Brasileiro imiscuir-se entre o processo civil e o processo incivil. Vejamos:

\footnotetext{
Doutor e mestre em Direito Processual Civil pela Faculdade de Direito da Universidade de São Paulo, Professor do Departamento de Direito Processual da Faculdade de Direito da Universidade de São Paulo. Desembargador no Tribunal de Justiça de São Paulo.

** Doutor e mestre em Direito Processual Civil pela Faculdade de Direito da Universidade de São Paulo. Professor dos cursos de Pós-Graduação lato sensu da Fundação Getulio Vargas FGVLaw e da Universidade de São Paulo. Advogado.
} 
“1. Esta aula teve o seu começo numa clara manhã de abril de 1964. Já estamos no outono de 2005 e eu ainda a estou a dar. Nesta noite, outonal por todos os títulos, termino eu de dá-la, mas não termina ela de ser dada. Saio eu. A Faculdade fica.

Para entender esta aula, é preciso entender a sua história. É preciso conhecer o seu começo.

Em novembro de 1963, incentivado por Luiz Eulálio de Bueno Vidigal, prestei meu concurso à livre-docência e, já para o ano letivo de 1964, fui por ele incumbido da regência da disciplina, que então ainda se chamava Direito Judiciário Civil, para o curso do terceiro ano diurno.

Em meados de março, começaram as aulas. Carregado de emoção, tive meu primeiro contato com a classe. A recepção que tive, absolutamente surpreendente, totalmente inesperada para quem nunca havia dado um dia de aula sequer nesta ou em qualquer outra Faculdade, aquela recepção sagrou-me, naquele dia e para o resto da minha vida, professor desta casa, da Faculdade de Direito de São Paulo. Os alunos de então, hoje respeitabilíssimos senhores e senhoras na casa dos sessenta anos, os alunos sim, bem mais do que o concurso precoce, ungiram-me com esta dignidade e me investiram dos ônus a ela inerentes.

Apenas iniciadas as aulas, sobreveio o golpe militar de 1964. Suspenderamse as aulas por alguns dias e, numa segunda-feira, ainda no mês de abril, reabriu-se a Faculdade. Se não me falha a memória, a minha aula era a primeira do dia. E a comecei dizendo: 'Meus senhores, terminou o processo militar. Vamos retomar o processo civil'.

Com estas palavras, eu não sabia, mas não tardaria vir a sabê-lo, eu acabava de empenhar o meu destino na perseguição de uma causa. Eu acabava de empunhar uma bandeira e de fincá-la no estrado de minha sala de aula, ao lado de minha mesa de professor, no estrado de todas as minhas salas de aula e de todas as minhas mesas de professor, como se a houvera fincado no centro do nosso pátio, no coração mesmo das nossas venerandas Arcadas. Motivo talvez para nunca me haver proposto lecionar em outras escolas.

Não era uma bandeira qualquer. Vim a sabê-lo depois. No seu tecido entrelaçavam-se panos ásperos de duras mortalhas, véus diáfanos de miríades de versos, grilhões rompidos de tenebrosos calabouços, o verbo incandescente daqueles para quem a vida reservou o encargo inexaurível de opor à tirania, a lei.

Com aquelas palavras, eu não sabia, eu acabava de empenhar o meu destino na defesa de uma causa: a da luta pelo Processo Civil e contra o processo militar.

Em termos mais simples afinal, pode-se perguntar, o que significa tudo isto? Eu vou explicar.

2. O Processo Civil e os processos militares têm algo em comum: põem em confronto a força do Estado e a força do povo, a força material do Estado e a força imaterial do povo. As coincidências param aí. 
As diferenças são muitas, mas podem ser sintetizadas no modo como atuam o Processo Civil e o processo não civil em relação à lei.

Ao processo militar a lei não importa, importa a disciplina; no mais das vezes, a lei é um estorvo a ser posto de lado enquanto os objetivos não são totalmente realizados, vencidas todas as resistências.

Se a lei foi cumprida, ou não, é indiferente.

Ao Processo Civil, ao contrário, a lei é tudo o que importa. Estorvo é tudo o que impeça o conhecimento exato do direito e o cumprimento exato da lei, único instrumento de defesa no confronto da sociedade civil com a potestade estatal, de defesa, antes de mais nada, da liberdade política do povo.

Dela advém, disse Montesquieu, a exigência de que os julgamentos 'nunca sejam mais do que um texto exato da lei', porque 'se fossem a opinião particular do juiz, viver-se-ia na sociedade sem saber precisamente os compromissos que nela são assumidos'. No mesmo sentido, advertia Locke, consistir a liberdade 'em não estar sujeito de modo algum à vontade inconstante, incerta, desconhecida, arbitrária, de um homem'. Aí se traça a linha divisória entre a liberdade e a tirania.

Relembrem-se, as palavras de Antígone, ressoando das profundezas dos séculos: 'esta é a vantagem dos tiranos: dizer e fazer tudo o que entendem'. O tirano é sempre a legibus solutus.

Daí haver sublinhado, ainda no século XIX, Francisco de Paula Baptista, ter o Processo Civil 'diversos períodos, que constituem a sua ordem natural, lógica e imutável, de tal sorte que não pode ser destruída ou ofendida, sem que se viole a justiça, e apareça a desordem ou tirania'.

Processo civil é isto. Nisto se condensa a alma do processo. Processo incivil é o seu oposto; é processo do qual nunca se sabe qual será o resultado, nunca se sabe se se conduziu com justiça, porque predisposto a ocultar, a camuflar, a impedir que apareça a desordem ou tirania.

3. Sabedores disto, deram os militares, assim que assumiram o poder, deram os militares início à destruição do Processo Civil. De pronto, suprimiram as garantias de vitaliciedade e estabilidade dos juízes, transformando-os, para usar uma expressão empregada por Piero Calamandrei, em 'strumentum regni'. No ano seguinte, ainda não satisfeitos, subtraíram ao conhecimento do Poder Judiciário, pelo Ato Institucional n. 2, 'os atos praticados pelo Comando Supremo da Revolução, com fundamento no Ato Institucional de 9 de abril de 1964, no presente Ato Institucional e nos complementares deste'. Não satisfeitos ainda, foram mais adiante. Pela Emenda Constitucional n. 7, de abril de 1977, submeteram os juízes brasileiros a uma hierarquia militar tendo como cúpula o Conselho Nacional da Magistratura, composto por ministros do Supremo Tribunal Federal (algo que se está reproduzindo hoje sub specie do Conselho Nacional 
de Justiça); conferiram ao Supremo Tribunal Federal o poder de avocação de causas, em detrimento do princípio do juiz natural (o que também reaparece hoje na argüição de descumprimento de preceito fundamental), e impuseram ao Supremo o rebaixamento maior: o dever de responder consultas prévias do Procurador-Geral da República, sobre como seria interpretada alguma lei caso esta interpretação tivesse que ser discutida em algum caso concreto: a chamada interpretação em abstrato, costume que a Inglaterra, trezentos anos antes já repudiara. $\mathrm{O}$ que também ressurge na atualidade, sob a forma da 'interpretação conforme', nas ações de declaração de constitucionalidade.

Foi este o começo da destruição imposta ao Processo Civil brasileiro para a sobrevivência dos ideais que inspiram o processo militar. Foi só o começo. Golpe mais profundo foi vibrado em 1984, já agora por mãos não militares, mas francamente autoritárias, herdeiras do império já então em franca derrocada.

4. Criaram-se em 1984, com grande alarde, como é próprio das instituições totalitárias, os Juizados de Pequenas Causas, cujo projeto ocultava objetivos inconfessáveis.

Do projeto submetido à discussão das entidades representativas da sociedade civil, as Universidades inclusive, constava: 'Art. 5. ${ }^{\circ}$ - O juiz decidirá com base na lei, atendendo aos seus fins sociais, às exigências do bem comum, adotando em cada caso a solução que reputar mais justa e eqüânime'. Um pastiche aparentemente inocente, que chamava a atenção pelo aberto contraste com a norma do art. 57 do mesmo projeto, que dizia: 'Não se admitirá ação rescisória nas causas sujeitas ao procedimento instituído nesta lei'. Ou seja, deveria o juiz decidir com base na lei mas, se decidisse contra a lei, prevaleceria sua decisão do mesmo modo.

A incompatibilidade se desfez no texto da lei que acabou sendo aprovada. Cortando a exclusão da ação rescisória? Não: cortando a expressão 'com base na lei' . A norma ficou assim: 'O juiz adotará em cada caso a decisão que reputar mais justa atendendo aos fins sociais da lei e às exigências do bem comum'. Ficou dispensado o juiz de decidir com base na lei, o que guarda conformidade com a exclusão da ação rescisória por ofensa a disposição literal da lei, mas é incompatível com a Constituição Federal.

Estava criado, enfim, um processo onde não vigoraria, como de fato não vigora, o princípio da legalidade, segundo o qual ninguém pode ser obrigado a fazer ou deixar de fazer alguma coisa senão em virtude de lei. Pior do que isto, a escolha entre a ida ao Juizado de Pequenas Causas ou à Justiça Comum, onde mal ou bem ainda impera o princípio da legalidade, ficou relegada à opção do autor; e assim continua a ser hoje em dia a despeito da alteração da lei, quando foram substituídos os Juizados de Pequenas Causas pelos Juizados Especiais Cíveis e Criminais.

Estejam certos, meus senhores, mercê desta inovação, é o Brasil o único país do mundo em que cabe a uma das partes do litígio a escolha da lei pela qual a outra parte será julgada. 
Isto, porém, ainda estava longe de satisfazer o apetite tirânico e as inclinações despóticas, que informam o ideário do processo autoritário, incivil. Era apenas um balão de ensaio para experimentos mais contundentes.

5. Abafadas as vozes discordantes, inaugura-se em 1993 a era das minireformas do Código de Processo Civil. O seu carro-chefe viria por uma lei de 1994. A Lei n. 8.953. A pretexto de agilizar o processo, de resgatá-lo da incurável demora que a ele nunca se deveu, mas, sim, à permanente falta de recursos para operá-lo, quebrou-se a coluna vertebral do sistema.

Pela introdução da antecipação da tutela, partiu-se em dois a estrutura do processo de conhecimento, invertendo-se os termos da garantia constitucional do devido processo legal. A regra de que 'ninguém será privado de sua liberdade ou de seus bens sem o devido processo legal', foi substituída pela de que 'qualquer um pode ser privado de sua liberdade ou de seus bens sem o devido processo legal; benefício este que, após consumada a privação, lhe será integralmente concedido para que se queixe à vontade'.

Trasladou-se dos Juizados de Pequenas Causas para a Justiça Comum a desnecessidade de uma sujeição real e efetiva do resultado do processo ao império da lei. $\mathrm{Na}$ sua primeira fase, perante o juiz singular ou tribunal, satisfaz-se o processo com um juízo de verossimilhança, como na comédia de Pirandello, Così è (se vi pare): Assim é se lhe parece. Na segunda fase há ainda, em tese, alguma probabilidade, escassa é bem verdade, de fazer reverter a decisão. Menos, bem menos provável, a de reverter a situação de fato criada pela antecipação da tutela.

Ciente deste risco, a despeito de remotíssimo, aprestou-se a vocação autoritária a ir à busca da consolidação das sentenças de primeiro grau, enfraquecendo o quanto possível, e cada vez mais, o controle pelos tribunais da conformidade da sentença com a lei. Sirva de exemplo a supressão do efeito suspensivo da apelação contra sentença que confirma a antecipação de tutela. É este apenas um exemplo. Muitos outros podem ser lembrados.

6. Mediante novas alterações do Código de Processo Civil, passaram os recursos a poder ser decididos, em boa parte, não mais por um órgão colegiado, mas por um segundo juiz singular, o Relator, perdendo o Tribunal a sua feição constitucional. Cada Relator, por sua vez, passou a poder dispor oficialmente de um ou mais assessores, que nem juízes precisam ser e são escolhidos pelo Desembargador ou Ministro ad libitum, a despeito de pagos pelo erário.

Não para aí a descaracterização, o desfiguramento, dos Tribunais. Surgem no Tribunal de Justiça as novas 'Câmaras A', constituídas só por juízes de primeiro grau com funções de desembargadores, posto a que não foram alçados por nenhum critério legal. São chamados de substitutos em segundo grau, que a ninguém substituem, o que 
é expressamente proibido pelo art. 107 da LOMAN (Lei Orgânica da Magistratura Nacional).

Isto, porém, ainda não é tudo. Para limpar o estoque de processos inventaram-se 'mutirões', nos quais as causas não são julgadas pelos seus juízes naturais, mas por outros quaisquer que se interessem por perceber o chamado 'auxílio sentença', obrigando-se a receber quarenta processos para serem decididos em trinta dias, rompido acintosamente o princípio do juiz natural.

Assiste-se hoje, promovida abertamente, a terceirização da Justiça.

O resultado de tudo isto, como não poderia deixar de ser, são decisões destituídas de autoridade, com as quais os vencidos não podem, nem devem, se conformar; o que gera mais recursos e maior oposição à execução das sentenças. $\mathrm{O}$ arsenal do processo incivil é vasto, porém, soluções tirânicas há para tudo e já estão sendo introduzidas na lei.

7. Para suprir a falta de autoridade das decisões judiciais foi introduzido no Código de Processo Civil um sistema punitivo que se alastra cada vez mais, indo das mais diversas sanções pecuniárias até a prisão civil, nada importando o quanto isto seja proibido pela Constituição da República. Há o escopo inocultável de silenciar os advogados, inclusive os que nunca se afastaram do exato cumprimento dos deveres que a ética lhes impõe, numa tentativa aberta de criminalização da advocacia. Institucionalizase uma nova forma de Terror: o terrorismo judicial.

A serviço desse novo Terror, inventou-se até um novo delito, uma nova hipótese de punibilidade: o descumprimento pela parte de provimentos mandamentais. Quem quer que se dê ao trabalho de empenhar-se verdadeiramente no estudo das sentenças mandamentais verá que a hipótese de descumprimento de sentenças mandamentais por ato da parte é uma contradictio in terminis. Ou a sentença comporta descumprimento pela parte e, neste caso, não é mandamental; ou a sentença é mandamental e não é suscetível de descumprimento pela parte.

Por outro lado, para diminuir a resistência à execução das sentenças está sendo paulatinamente minado o direito de defesa do devedor. Muito já se fez nesta senda e mais está por fazer-se, com a eliminação dos embargos à execução.

A pouca resistência à abertura dessas fendas; no sistema processual tem sido um incentivo a que outras se abram, mas audazes, como a da estabilização do resultado das tutelas antecipadas e a desestabilização da coisa julgada, esta sim uma verdadeira pá de cal no processo civil.

8. Em suma: o processo civil está sendo metodicamente destruído; o processo incivil progride; o império da lei claudica.

Lutei contra isto. Todos aqui sabem da minha luta. Travei-a por mais de quarenta anos, principalmente no estudo e na docência do Direito Processual Civil. Documentei-a em alguns escritos: Da ação civil, de 1973; O princípio da liberdade na 
prestação jurisdicional, de 1980; A crise do Judiciário, O desmantelamento do sistema brasileiro de controle de constitucionalidade, As novas tendências do direito processual: uma contribuição para o seu estudo, todos de 2002; A revisão do Código de Processo Civil, de 2004; A nova execução de sentença, de 2004; A coisa julgada, deste ano de 2005.

Tudo isto, porém, é muito pouco, é quase nada, mas coloca uma questão. Suscita uma pergunta: como foi tudo isto possível à vista do povo, em pleno regime democrático, à luz do dia, sem que um levante irreprimível se erguesse em defesa da lei, do direito e do devido processo legal?

A resposta, meus senhores, é dura, mas é sabida e ressabida. O que falta é conhecimento do Direito.

O conhecimento atual é tão estreito, é tão superficial, tão desalinhado, que não permite aos operadores do direito dar-se conta de que lhes está sendo subtraído o senso crítico, tornando-os presa fácil de uma propaganda enganosa, fiada exclusivamente no sucesso que tem granjeado a indevida imputação, ao processo civil, de toda a culpa pela demora no andamento das causas. Como se outro remédio não houvesse para coarctála, senão cortar, retalhar, amortalhar as instituições processuais.

O que está acontecendo comprova que a universidade não está formando os quadros necessários para defender os direitos fundamentais do homem, os direitos sem os quais não é possível a evolução do homem, a convivência entre os justos, o progresso dos homens de boa vontade.

Formar estes quadros, porém, não é obra impossível. Longe disto. Nem é obra de custos inacessíveis. É obra que demanda alguns passos que têm seu custo, alto sem dúvida, mas demanda muitos outros passos que não custam nada.

Permito-me assinalar alguns deles.

1) Precisamos ter humildade. Precisamos reconhecer que o Brasil é um país culturalmente pobre e que não dispõe de recursos suficientes para pagar professores de graduação e de pós-graduação.

Dentre os bons professores de que dispomos, temos que escolher os que responderão pela graduação e os que responderão pela pós-graduação. Temos que escolher com base na excelência: os melhores devem ser incumbidos da graduação. Quanto menor o conhecimento do aluno, tanto maior terá que ser o do seu professor. Professores titulares devem dedicar-se integralmente à graduação e à orientação, só orientação, de pós-graduandos. Da pós-graduação devem ficar incumbidos os livre-docentes. As aulas e outros trabalhos excedentes à capacidade dos titulares e livres-docentes, sejam atribuídos aos doutores. E a cada um não se imponha trabalho que exceda à remuneração possível, atendidas as regras do mercado de trabalho. Especialmente, evite-se ao máximo o desperdício de tempo dos docentes em atividades meramente administrativas que hoje se distribuem por uma infinidade de colegiados e comissões perfeitamente dispensáveis. 
2) Precisamos nos convencer de que, querendo ou não, a nossa sociedade, devastada por um consumismo avassalador, não permite que um aluno de Direito viva sem trabalhar, que disponha de tempo para estudar. Não tem. Os objetivos do ensino têm que tomar como premissa esta limitação.

Por isto, a aula teórica tem que ser expositiva, para formar a base do conhecimento, e tem que ser crítica, para que o aluno desenvolva inteligentemente a sua aptidão de não se conformar com tudo que está escrito em letra de forma. O que ele tiver que aprender irá aprender em classe. Os exames serão sua única oportunidade de trabalhar com a matéria que lhe é transmitida. As provas têm que ser corrigidas pelo professor que ministrou a matéria, não importa o seu grau, nem sua idade. A revisão de provas, em diálogo aberto com o aluno, tem que ser a regra, não a exceção. É o único momento em que ao professor é dado auxiliar verdadeiramente o aluno a vencer suas limitações.

3) A Faculdade tem que defender sua autonomia didática e científica, porque, o Estado brasileiro está empenhado na destruição da Universidade. Se isto já é assim de há muito, hoje está pior.

Atrelarmo-nos aos desígnios de quem não conhece a matéria de que somos mestres, não é apenas descrer de nossa mestria, é nos deixar escravizar por quem, da nossa matéria, nada sabe, absolutamente nada. Por exemplo, linhas de pesquisa em Direito são algemas que só nos atrasam.

4) Para que a atividade docente prospere, a disciplina é fundamental. $\mathrm{O}$ professor tem que ser disciplinado, tem que pôr fora a sua vaidade e submeter-se religiosamente às justas expectativas de seus alunos, que nesta Faculdade, são das mais altas do País. Por exemplo, não pode ministrar uma aula que não tenha preparado antes, por maior que tenha sido o número de vezes que a tenha dado; se não a pôde preparar, é melhor que não a dê. O que disciplina o aluno é a disciplina do professor.

5) Por último, no conflito entre seus interesses particulares e os interesses do ensino do Direito, deve o professor, sempre, dar prioridade a estes sobre aqueles.

Meus senhores, é soada enfim a minha hora. A despeito de o mar estar revolto e serem contrários muitos dos ventos, retine seco o sino que indica o fim do meu turno. É hora de entregar a mãos mais descansadas a roda do leme, o comando da navegação.

Nesta hora derradeira, seja-me permitido dizer da Faculdade de Direito o que em versos disse Martins Fontes da terra de São Paulo:

De minha terra, para minha terra

Tenho vivido. Meu amor encerra

A adoração de tudo quanto é nosso.

Por ela sonho num perpétuo enlevo

E, incapaz de servi-la o quanto devo, 
Quero ao menos amá-la o quanto posso. (MESQUITA, 2006, p. 250-257).

O saudoso Professor Mesquita faleceu, em São Paulo, no dia 20 de junho de 2014. O grupo de estudiosos, ligados ao pranteado Mestre, emitiu, no dia seguinte, comovente necrológio, aqui parcialmente transcrito:

No último sábado (21.06.2014), nos despedimos de nosso mestre, Professor José Ignacio Botelho de Mesquita, que nos deixou no dia anterior. Mais que Professor Emérito da Faculdade de Direito da Universidade de São Paulo e Professor Titular de Direito Processual Civil, Patrono e Paraninfo de tantas turmas da mesma Faculdade, o Professor Mesquita sempre foi admirado e adorado por seus alunos e sempre se colocou à disposição de todos aqueles que queriam se dedicar ao estudo do Direito Processual Civil. Conosco não foi diferente. Vindos de diferentes origens, em diferentes fases da vida acadêmica, mas com o objetivo comum de nos aprofundarmos no estudo do Direito Processual Civil, na noite de 18 de maio de 2005 houve nossa primeira reunião no escritório do Professor Mesquita, quando teve início o 'Grupo de Estudos JIBM'. Durante os últimos nove anos, tivemos reuniões periódicas, em alegre e profícuo convívio com o mestre. Tais encontros, algumas vezes seguidos de memoráveis jantares, além de estreitar os laços de amizade e aumentar nossa admiração pelo homem e pelo professor, renderam inúmeros estudos..., todos publicados em periódicos ou coletâneas e marcados pela preocupação de trazer ferramentas práticas para auxiliar os profissionais em sua vida cotidiana. Talvez por simbólica coincidência, a primeira noite após nossa despedida do Professor Mesquita foi a mais longa do ano, marcando o Solstício de Inverno. E, neste ano, além de a mais longa, para nós foi a mais escura, pois se apagou a estrela mais brilhante de nossa constelação. No entanto, desde as culturas mais antigas, o Solstício de Inverno traz em si a ideia de renascimento, de reinício. Havia nesta data, inclusive, a Festa do Sol Vencedor, pois após esta noite, todas as seguintes tornam-se mais curtas e os dias mais longos, marcando a vitória do Sol sobre as trevas. Portanto, apesar desse momento de tristeza e despedida, nos comprometemos com a ideia de reinício para que, mesmo no escuro da ausência de nosso mentor, continuemos com nossos estudos sobre o Direito Processual. Mas o efetivo Processo Civil, e não o 'Processo Incivil' que, nas palavras do mestre em seu discurso de despedida da vida acadêmica, nas Arcadas, foi assim definido: 'Processo incivil é o seu oposto; é processo do qual nunca se sabe qual será o resultado, nunca se sabe se se conduziu com justiça, porque predisposto a ocultar, a camuflar, a impedir que apareça a 
desordem ou tirania' (RePro 131/250)... (TUCCI, 2020, p. 128-130).

Esse necrológio foi subscrito pelos seus ex-alunos que figuraram nesses encontros: Daniel Guimarães Zveibil, Guilherme Silveira Teixeira, Luiz Guilherme Pennacchi Dellore, Débora de Oliveira Ribeiro, Mariana Capela Lombardi Moreto, Rodolfo da Costa Manso Real Amadeo, Susana Amaral Silveira e Walter Piva Rodrigues.

Arcadas, 27 de outubro de 2020.

\section{Referências}

MESQUITA, José Ignacio Botelho de. Processo civil e processo incivil. Revista de Processo, São Paulo, v. 31, n. 131, p. 250-257, jan. 2006.

TUCCI, José Rogério Cruz e. A cátedra de processo civil no Largo de São Francisco. São Paulo: Migalhas, 2020. 